\title{
A fabricação de uma cidade tóxica: A Tribuna de Santos e os desastres tecnológicos de Cubatão (Brasil) na década de 1980
}

\author{
The fabrication of a toxic city: A Tribuna de Santos
}

newspaper, and technological disasters in the 1980s

\author{
Jo Klanovicz ${ }^{*}$ \\ Clayton Barbosa Ferreira Filho**
}

\author{
Palavras-chave: \\ Cubatão (cidade brasileira) \\ Desastres \\ Imprensa
}

Keywords:

Cubatão (Brazilian city)

Disasters

Press

\begin{abstract}
Resumo: Este artigo discute a fabricação do Município de Cubatão, Brasil, como espaço tóxico e de poluição na década de 1980. Entende-se a toxicidade como uma construção ao mesmo tempo material e discursiva, baseada nas ansiedades da sociedade industrial. Para discutir a questão, utiliza-se o jornal A Tribuna de Santos, que foi o principal espaço de publicação de matérias sobre desastres ambientais na região. $\mathrm{O}$ texto discute o tema levando em consideração a relação entre desastres ambientais e perspectivas desenvolvimentistas articuladas durante o mais recente regime autoritário brasileiro.
\end{abstract}

Abstract: This article stresses the fabrication of Brazilian city of as a toxic place in the 1980s. Toxicity is taken as a material and discursive construction, based on anxieties of industrial society. To discuss the issue, we use the newspaper A Tribuna de Santos, which was the main publisher of environmental discussions on disasters in the region of Cubatão. We discuss this issue observing the relationship between environmental disasters and development perspectives articulated by the later Brazilian authoritarian regime.

Recebido em 22 de setembro de 2017. Aprovado em 22 de dezembro de 2017.
Neste artigo, buscamos discutir, do ponto de vista de uma história voltada às questões ambientais, o trabalho de denúncia e problematização da poluição em Cubatão, São Paulo, por parte da imprensa na década de 1980, entre os últimos anos do regime militar e o movimento de redemocratização e a emergência de novas ou diferentes posturas públicas acerca de temas ambientais que envolvem diretamente a saúde das populações humanas.

A partir do segundo pós-guerra, o Brasil tem sido palco de inúmeros projetos de modernização, imersos num universo muito característico e vigoroso na história recente do país: o desenvolvimentismo. Muitos dos projetos iniciados nos anos 1950 já indicavam, duas décadas depois, o que o historiador Warren Dean (2000) veio a qualificar como exemplos de "desenvolvimentos insustentáveis", ou seja, "projetos que atingiram um clímax que não resultou apenas em crise econômica, mas também em uma tempestade conjunta de desastres ambientais" (DEAN, 2000, p. 307). Em meio às teias de relações funcionais das peças da modernização, tais como industrialização, a urbanização acelerada, as migrações e as novas relações entre cidade e desenvolvimento, Cubatão/SP acabou simbolizando o sucesso do desenvolvimento industrial, mas também os dilemas do desenvolvimentismo, especialmente aqueles ligados à tecnologia de força bruta. Representada de diversas maneiras ao longo do tempo, Cubatão conseguiu ser descrita como "locomotiva do Brasil" nos anos 1950, "marco do desenvolvimento" e "cidade técnica" nos anos 1970. Nos anos 1980, o município passou a ser descrito como um

\footnotetext{
* Docente e orientador no Programa de Pós Graduação Interdisciplinar em Desenvolvimento Comunitário e no Programa de Pós-Graduação em História, da Unicentro. Coordenador do Laboratório de História Ambiental e Gênero (LHAG), bolsista produtividade CNPq. E-mail: <klanov@ gmail.com>.

** Mestre em História (Unicentro, 2015). Professor do Colégio Estadual Campo Magro, Paraná. E-mail: <claytonbffilho@gmail.com>.
} 
território tóxico e espaço de desenvolvimento e progresso perdidos. A brutalidade das políticas desenvolvimentistas veio a ser questionada na imprensa regional em termos específicos, como nos casos de nascimento de crianças anencéfalas $(\mathrm{O}$ ESTADO DE SÃO PAULO, ESP, 4 de fevereiro de 1981) ou natimortas (ESP, 18 de fevereiro de 1982), a ocorrência contínua de chuvas ácidas (FOLHA, 12 de junho de 1984), explosões e incêndios (A TRIBUNA DE SANTOS, TS, 26 de fevereiro de 1984), enxurradas, vazamentos de resíduos tóxicos, contaminação de rios, lençóis freáticos, intoxicação de animais (TS, $1^{\circ}$ de março de 1986) ou chaminés cuspindo gases tóxicos 24 horas por dia durante décadas (FERREIRA, 1991, p. 79).

As máscaras colocadas pela imprensa sobre Cubatão não estão distantes do contexto de onde emergiram os discursos de toxicidade, de contaminação, de poluição e de morte nas sociedades industriais tardias do século XX. Lawrence Buell (2011) observa que a toxicidade é um conjunto interconectado de temas cuja força deriva em parte das ansiedades da cultura industrial e em parte de hábitos profundamente enraizados de pensamento e expressão (BUELL, 2011, p. 30). O tóxico, o contaminante, o poluente, dessa forma, emergem dos pânicos individuais e sociais e de uma base evidencial nos fenômenos ambientais (BUELL, 2011, p. 31).

Pensar desastres ambientais como os de Cubatão, nesse sentido, significa entender como ao longo do tempo segmentos sociais, por meio de suas relações com o ambiente, tem produzido ou intensificado a ocorrência de eventos dessa natureza (ESPÍNDOLA; NODARI; LOPES, 2013; 2015). Escapando aos embates epistemológicos nas Ciências Sociais acerca da categorização de desastres, porém sem deixar de observar os gatilhos que desastres tecnológicos acionam (OLIVER-SMITH, 1999, p. 19), eventos como os de Cubatão permitem visualizar, também, a "política na história, a partir da intersecção tecnologia-natureza-sociedade, ponto onde as temáticas sociais, ambientais, científicas e políticas são marcadamente híbridas" (KLANOVICZ, 2013, p. 294).

Entende-se que esses desastres ambientais ocorrem devido a configurações que condicionaram os processos sócio-históricos da industrialização brasileira, fruto da política desenvolvimentista, que no anseio de inverter a política econômica importadora para exportadora investiram pesado na industrialização do país (FERREIRA FILHO, 2015, p. 16).

O momentum ambiental da emergência de Cubatão como espaço tóxico na imprensa precisa também ser pensado à luz das relações entre estado autoritário, populações humanas e mundo natural, sua violência com relação às pessoas e ideias, e sua voracidade com relação aos recursos naturais e ao controle de paisagens.

A TS exerceu papel crucial na exposição dos problemas ambientais em Cubatão/SP. Entre as páginas do jornal, buscamos interpretar as percepções sobre os problemas ambientais, tomando-os como discursos que verbalizam as ansiedades contemporâneas sobre a relação entre humanos, mundo natural, cidade e desenvolvimento. Paulatinamente, o periódico foi construindo uma crítica pontual sobre a cidade técnica, sobre o uso de tecnologia, sobre o desenvolvimentismo na sua versão autoritária a partir da exposição de casos de contaminação ambiental, tratados como problemas de saúde pública. Nesse sentido, argumentamos que o jornal, ao tratar desastres ambientais a partir do foco da saúde pública, proporcionou a emergência e algumas bases do que veio a se constituir como uma imprensa ambientalmente preocupada no Brasil da segunda redemocratização.

Este artigo foi construído a partir de uma pesquisa documental amparada em exemplares do jornal em foco, a TS, cotejado com outras produções acerca de desastres e ligados à história da modernização e do desenvolvimentismo no país. Buscamos apresentar o tema contextualizando Cubatão/SP na perspectiva ideológica do desenvolvimentismo brasileiro para depois darmos atenção às maneiras que a imprensa constrói sua visão acerca dos fenômenos ambientais marcantes do município.

\section{Cubatão e o desenvolvimentismo}

A partir da década de 1910, algumas fábricas começaram a habitar a cidade, tais como 
a Companhia Curtidora Marx (1912-1914), adquirida pela empresa Costa Moniz em 1919, a Companhia Santista de Papel (em funcionamento a partir de 1922), que demandava energia proveniente da primeira hidrelétrica brasileira (a Henry Borden), construída pela São Paulo Light and Power Company (1926), ou ainda a Companhia de Anilinas, Produtos Químicos e Material Técnico (fundada em 1913 e maior empresa do estado de São Paulo em 1928). A partir do final da década de 1940, uma nova realidade industrial regional, marcada pelo petróleo e pelas indústrias de base, criou um surto de desenvolvimento renovado (GOLDENSTEIN, 1972, p. 113), favorecido pelo lançamento do Plano Nacional Rodoviário (1945) e a subsequente inauguração da rodovia Anchieta (1947), a instalação da Comissão de Estudos do Oleoduto Santos-São Paulo-Campinas, com posterior construção do mesmo entre 1948 e 1952, e a criação da Refinaria Presidente Bernardes Cubatão (RPBC), inaugurada em 1955 e primeira refinaria de petróleo do país. Papel decisivo na instalação da refinaria em Cubatão foi atribuído ao coronel Arthur Levy (1902-1993). ${ }^{1}$

O incremento da industrialização brasileira, a partir dos anos 1960, fez com que o governo federal fosse obrigado, de um jeito ou de outro, a incrementar a produção e distribuição de energia, de combustíveis, bem como incentivos à metalurgia, siderurgia e indústria química, o que aumentou a ferocidade das chaminés que alimentavam o ideal desenvolvimentista. Cubatão passou a ser Área de Segurança Nacional (Lei 5.449/1968), o que, se não inviabilizou intervenções e influências de políticos locais na região, serviu à construção de um novo discurso sobre a cidade, baseado na indústria pesada legitimada pelos ideários do crescimento e progresso econômicos do país. Nascia, a partir da área de segurança nacional, o que alguns setores sociais chamaram de "cidade técnica".

Esse cenário só foi se agravando durante a década de 1970, quando empresas multinacionais, como a francesa Rhodia, descartavam resíduos industriais da fábrica de pentaclorofenato de sódio em rios, em loteamentos e áreas de Mata Atlântica da Baixada Santista, prática também adotada pela norte-americana Union Carbide, que fabricava o pesticida Temik 10G, a base do carcinogênico isacianato de metila. Essas e outras empresas escreviam uma história de contaminação de áreas que estavam distantes até $70 \mathrm{~km}$ do polo industrial de Cubatão, o que veio a ser verificado posteriormente. No entanto, estas mesmas razões de interesse geopolítico e militar foram também as condicionantes para a proliferação e que acionaram os desastres em Cubatão. Sendo assim, estas mesmas razões que levaram Cubatão se tornar Ârea de Segurança Nacional - como a "defesa natural" imposta pela serra e a proximidade com o Porto de Santos - também acabaram por fazer de Cubatão ser vista como uma "área de insegurança nacional" (TS, 24 dez. 1984), fazendo com que se questionassem todos os frutos da política desenvolvimentista.

Em uma região que está no pé da serra geral, com ventos fracos vindos do mar em direção à serra, bem como a baixa velocidade dos rios que conectam o continente ao mar a partir de extenso mangue, Cubatão é local peculiar de acumulação de gases poluentes que não se dissipam com facilidade. Por outro lado, no mangue, as condições faziam com que aumentasse a concentração de resíduos sólidos, que não são levados ao mar facilmente devido, entre outros fatores, à ação das marés, à presença de aterros, à interrupção de fluxos naturais e à modificação da paisagem (HOGAN, 1988, p. 344).

É nesse ambiente (tomado aqui o termo como uma mútua dimensão natural e construída do mundo palpável) que, entre os anos 1970 e 1980, diversos eventos desastrosos, mas também resistências sociais fizeram vir à tona uma agenda ambiental que, obrigatoriamente, transbordou na política e como a poluição foi sendo atrelada a problemas de saúde pública, não tardaria muito para que o mito de uma cidade técnica, em um governo militar que se pretendia igualmente técnico, começasse a ruir.

Pensar desastres significa discutir seletividades. Um dos pontos fundantes da imagem de Cubatão como espaço de desastres foi o Vale da Morte. Foi o "fim do silêncio sobre o que acontecia em Cubatão” (FERREIRA, 1991, p. 32). Dessa forma, não há elemento mais fundamental para 
verbalizar as ansiedades em torno da toxicidade e da exposição das cidades aos agentes nocivos da modernização industrial no Brasil contemporâneo, do que a imprensa que começava a percorrer o itinerário dos problemas ambientais ainda em meio à ditadura militar. Embora a grande imprensa tivesse um interesse primordial no trato de questões ambientais, qual seja o interesse econômico em detrimento da mensagem ambiental (RAMOS, 1995).

Elenita Malta Pereira (2016) pontua, por exemplo, o papel determinante da imprensa escrita gaúcha no início de uma campanha contra a poluição causada pela Celulose Borregaard, empresa norueguesa que se instalou nas margens do rio Guaíba, em Porto Alegre. Juntas, Folha da Tarde, Correio do Povo, Jornal do Comércio, Zero Hora e Folha da Manhã não pouparam criatividade e matérias e articulavam preocupações públicas e entidades como a Associação Gaúcha de Proteção ao Ambiente Natural (AGAPAN) contra a empresa, em 1972, simultaneamente à realização da Conferência Mundial sobre o Homem e o Meio Ambiente (5-16 de junho de 1972). Pereira (2016) reproduz em seu trabalho documento de uma das reuniões preparatórias de políticos brasileiros para a conferência, uma comunicação interna, de Eleazar Savio, posição do Ministério das Relações Exteriores: “(...) que não nos interessa água pura e ar puro se não temos emprego e, consequentemente, dinheiro para comprar o que comer. O Brasil prefere ter um ar menos puro, um solo menos puro, águas menos puras, mas uma indústria que dê condições econômicas ao povo e ao governo para se desenvolver. Esse é o ponto básico."

É por meio dessa imprensa que as condições de vida em Cubatão vêm à tona desde os anos 1970, em um processo de problematização da contaminação e da poluição, que já estava sendo pautado, porém sem que se questionasse suas bases econômicas. Isso pode ser percebido, por exemplo, quando lemos o Decreto 76.389, de 1975, que dispõe sobre medidas de controle da poluição industrial no Brasil.

Depois de conceituar poluição industrial a partir de uma leitura estreita e de caráter físicoquímico,odecretoestabelecequeaadoçãodemedidas de prevenção ou controle da poluição deveria levar em conta a "capacidade autodepuradora da água, do ar e do solo, bem como a necessidade de não obstar indevidamente o desenvolvimento econômico e social do País" (Decreto 76.389, art. 3, parágrafo único). O decreto já pontuava Cubatão como área crítica de poluição no âmbito do II Plano Nacional de Desenvolvimento (II PND). ${ }^{2}$ Foi justamente no âmbito do II PND que o próprio governo federal foi obrigado a constatar a desaceleração econômica do país, especialmente entre os anos de 1976 e 1977, o que veio a colocar o modelo de crescimento em crise (FARO, 2010, p. 81).

\section{Histórias nefastas da cidade "técnica": e o fim do "silêncio" da imprensa sobre os problemas ambientais}

Dean (2000) pontuou que a perspectiva desenvolvimentista brasileira era muito mais do que uma política; ela penetrava a consciência da cidadania, justificando cada ato de governo e até de ditadura, e de extinção da natureza, e quase a totalidade das ações de desenvolvimento entre as décadas de 1950 e 1970 estavam confinadas a regiões da Mata Atlântica (DEAN, 2000, p. 281).

Aolongo da história do desenvolvimentismo no Brasil, Cubatão perfaz um caminho de encontros e desencontros entre política, ciência, tecnologia e controle da natureza, com consequências socioambientais profundas e internacionalmente debatidas. Momento fundamental para se pensar o aprofundamento dos problemas ambientais da cidade foi a sua transformação em Área de Segurança Nacional, como já mencionado. O primeiro prefeito de Cubatão após o decreto de segurança nacional foi o engenheiro sanitário Aurélio Araújo para prefeito de Cubatão (HALLISON, 1970, p. 8), descrito como "um técnico para administrar uma cidade de técnica" (HALLISON, 1970, p. 8), especialista em urbanismo público.

É interessante notar que se tratava de uma cidade técnica, "marco do desenvolvimento", mas que não tinha sequer rede de esgoto ou rede de canais de drenagem dos rios urbanos. Como uma cidade descrita como técnica carecia dos 
próprios mecanismos técnicos que serviam como denominadores comuns do que se pode chamar um processo de modernização? É no âmbito de uma crise instalada no modelo de desenvolvimento que Cubatão/SP precisa ser vista no que tange à escala de desastres ambientais entre as décadas de 1970 e 1980, cujas consequências vieram a despertar atenção da comunidade científica, de movimentos e associações populares e da imprensa. ${ }^{3}$

As fissuras na barreira que enfraquecia a problematização das questões ambientais do município começaram a aparecer quando o Instituto de Oceanografia da Universidade de São Paulo detectou, em 1975, nível exorbitante de mercúrio na região $(2 \mu \mathrm{g} / \mathrm{l}$ a $5 \mu \mathrm{g} / \mathrm{l}$ de água, ou seja, 25 vezes maior do que o máximo recomendado pela Organização Mundial de Saúde). Às constatações técnicas seguiram-se apropriações políticas, mesmo considerando que Cubatão não desfrutava de um cenário favorável ao embate político por ser Área de Segurança Nacional. Em 1978 foi criada uma Comissão Especial de Vereadores para apurar denúncias de possíveis relações entre a poluição e a saúde de trabalhadores da cidade (FERREIRA, 1991, p. 62). A comissão teve importante papel ao expor a contaminação de trabalhadores da multinacional francesa Rhodia por pentaclorofenato de sódio (Pó da China), produzido pela Unidade Química de Cubatão (UQC).

A repercussão do problema fez com que a Assembleia Estadual de São Paulo criasse uma Comissão Especial de Inquérito para "apurar possíveis irregularidades no município de Cubatão e dar soluções aos problemas da poluição ambiental" (FERREIRA, 1991, p. 64; COUTO, 2003, p. 168), tendo por base a exposição dos casos de anencefalia da Vila Parisi (FERREIRA, 1991, p. 70-74). Depoimento do jornalista Randáu Marques, que à época trabalhava no Jornal da Tarde e que cunhou o termo "Vale da Morte" para qualificar a situação contemporânea de Cubatão, descrevia à comissão o cenário catastrófico do município e da Vila Parisi, salientando os danos que a COSIPA causou ao lotear o mangue que acabou dando lugar a barracos (FERREIRA, 1991, p. 102). Em 2 de dezembro de 1981, a revista Veja publicava a matéria “O inferno de Cubatão", na qual os casos de anencefalia da Vila Parisi ganhavam repercussão nacional (Veja, 2 de dezembro de 1981, p. 50).

Diante dos problemas advindos da acelerada industrialização, por meio de uma declaração pública da Companhia Ambiental do Estado de São Paulo (CETESB), onde, a pedido da promotoria da $1^{\text {a }}$ Vara de Cubatão, esta primeira reconhece a possibilidade de ocorrer uma catástrofe em Cubatão por meio de um relatório sobre a qualidade do ar (FERREIRA, 1991, p. 79; COUTO, 2003, p. 168). Com o reconhecimento da CETESB de que a poluição do ar comprometera a vegetação da Serra do Mar, e consequentemente tornara a vida da população que habita as encostas e vales ainda mais vulnerável a deslizamentos, a relação entre desenvolvimento econômico e desastres ambientais começou a deixar de ser um discurso contra a soberania nacional e passou a ter mais atenção por parte de diversos segmentos sociais e setores do estado brasileiro.

Na madrugada de 24 para 25 de fevereiro de 1984, um vazamento de 700 mil litros de gasolina do Oleoduto Santos-São Paulo causou a explosão da tubulação que passava por baixo das palafitas que sustentavam uma favela chamada de Vila Socó, na altura do km 57 da Rodovia Anchieta, ocasionando o incêndio de 470 moradias e provocando a morte de 93 pessoas, de acordo com dados oficiais da época, ainda controversos. A tragédia talvez seja o maior dos desastres de Cubatão e teve repercussão nacional e internacional. ${ }^{4}$ Um dia após o desastre, TS dá início a uma série especial de reportagens sobre a Vila Socó, intitulada Tragédia em Cubatão. Várias matérias foram publicadas até 4 de março de 1984. O jornal afirmava que metade da vila fora destruída pelo fogo, que teve início entre $24 \mathrm{e}$ 25 de fevereiro, e que durou sete horas (TS, 26 de fevereiro de 1984). O jornal criticava autoridades locais, estaduais e nacionais, lembrando que a Petrobrás não podia justificar o evento com o argumento da imprevisibilidade, haja vista a falta de manutenção dos oleodutos e os casos anteriores de vazamento de gasolina neles e as próprias declarações do presidente da empresa à época, Shigeaki Ueki (TS, 26 de fevereiro de 1984). Um 
advogado da região, Vicente Cascione, afirmava que o governo apenas dava voz a "técnicos, entre aspas, a dar explicações e desculpas repugnantes. Chefes buscando fugir às responsabilidades. Autoridades, entre aspas e entre pelotões de segurança, a vistoriar o que resta dos escombros" (TS, 26 de fevereiro de 1984). E continuava: "Amaldiçoada Cubatão, das soluções adiadas, das embromações e do abandono. Quantas tragédias ainda se escondem, na espreita, na perspectiva de cada madrugada? Mesmo esta catástrofe, que se anunciava desde horas antes, não foi evitada" (TS, 26 de fevereiro de 1984).

Em depoimento ao jornal, o chefe do Instituto Médico Legal, Carlos Afonso de Figueiredo, disse que em 33 anos de serviço nunca havia visto nada igual. Segundo o legista: "o maior problema para a identificação dos corpos é por estarem totalmente carbonizados. [...] Geralmente a identificação é feita pelo antebraço e dedos, mas nem isso restou" (TS, 26 de fevereiro de 1984). Diante do drama dos familiares para identificar os corpos dos parentes, o jornal afirmava que o que mais sensibilizava no centro comunitário (local onde estavam sendo recolhidos os corpos) era a imagem dos corpos das mães abraçadas aos filhos, além de enfatizar que, entre estes corpos de mães com seus filhos era possível ver o crânio de um bebê no ventre da mãe (TS, 26 de fevereiro de 1984).

Na capa da edição de 27 de fevereiro, a narrativa do pós-desastre em Vila Socó produzida pelo jornal manteve a retórica de sofrimento dos sobreviventes na tentativa de identificar os corpos de seus familiares. Nesta retórica de sofrimento dos familiares no pós-desastre, o jornal A Tribuna de Santos faz uma metáfora do desastre de Vila Socó com filme O Dia Seguinte (MEYER, 1983). Estreado no ano anterior ao desastre de Vila Socó (portanto, ainda recente na memória coletiva), o filme do diretor americano Nicholas Meyer explora os acontecimentos de uma guerra nuclear entre os Estados Unidos da América e a União Soviética durante a Guerra Fria. A metáfora feita pelo jornal foi de que os restos de Vila Socó na manhã de 25 de fevereiro só se comparavam a um ataque nuclear. Eram "tochas humanas na cidade-bomba" (TS, 27 de fevereiro de 1984). O governador de
São Paulo, Franco Montoro declarou que "este município está condenado desde que foi declarado Área de Segurança Nacional. O fato de o povo [...] estar impedido de participar das soluções de seus problemas também levou a isso" (TS, 26 de fevereiro de 1984). O presidente da Petrobrás, Shigeaki Ueki, afirmava não afastar a possibilidade de a culpa ser da empresa (TS, 26 de fevereiro de 1984). Embora admitisse a possibilidade de culpa, Ueki declarou que "não passou pela cabeça de nenhum técnico que isso pudesse ocorrer". O jornal contrapôs a declaração de Ueki baseando-se no testemunho de moradores, que denunciavam a negligência e a tentativa de acobertar o vazamento (TS, 26 de fevereiro de 1984).

Já na matéria Técnicos da Petrobrás não previram incêndio, o engenheiro da Petrobrás, Mário de Freitas Esteves, dizia que a culpa também era da prefeitura de Cubatão. Segundo ele, "a existência de barracos, de uma favela, sobre o oleoduto faz suspeitar que o fogo tenha começado por uma vela, algum foco de ignição. O local não tem luz" (TS, 26 de fevereiro de 1984). Por um lado, os técnicos da Petrobrás tinham razão em afirmar que a população não deveria habitar áreas próximas aos dutos por serem locais de risco. Mas a autonomia do município era extremamente relativizada por conta de ser Área de Segurança Nacional.

$\mathrm{Na}$ matéria do dia 29 de fevereiro, o jornal confirmou a negligência da Petrobrás através de uma manchete no topo da página a qual afirmava categoricamente "Petrobrás sabia do vazamento" (TS, 29 de fevereiro de 1984). Na matéria de 2 de março, o promotor público responsável pela investigação, Marcos Ribeiro de Freitas, relacionou cinco formas de culpa direta da Petrobrás: erro de alinhamento, negligência, mau estado da tubulação, ausência de manômetro e ausência de extintor (TS, 2 de março de 1984). Em 4 de março, nova denúncia, dessa vez afirmando que houve erro de comunicação entre as equipes do oleoduto na operação de bombeamento (TS, 4 de março de 1984).

Se por um lado o jornal $A$ Tribuna não discutia a contaminação do mangue com gasolina em Vila Socó, buscando trabalhar mais com a ideia do erro humano, o jornal não deixava de criticar a 
política desenvolvimentista, entendendo-a como um grande perigo para toda a região da Baixada Santista (TS, 9 de março de 1984). O risco residia na qualidade da balneabilidade das praias de São Vicente e Santos, ao abastecimento de água potável em toda a região, especialmente depois da decisão do Departamento Nacional de Águas e Energia Elétrica (DNAEE) de retomar o despejo das águas poluídas dos Rios Pinheiros e Tietê (São Paulo/SP) no lago da Represa Billings para abastecer a Usina Henry Borden em tempos de estiagem (TS, 9 mar. 1984). Nesse e em outros editoriais da Tribuna é possível perceber o aumento da frequência de discussões acerca de problemas ambientais da região. Em 28 de fevereiro, por exemplo, o jornal afirma que não apenas Cubatão sofria com os efeitos de uma industrialização desenfreada, e que, "na estrada de Santos, há outro vulcão que pode explodir a qualquer momento": o Terminal da Alemoa, onde eram armazenados diversos produtos químicos utilizados pelas indústrias de Cubatão (TS, $28 \mathrm{de}$ fevereiro de 1984).

\section{O gás da Î́ndia chega à baixada santista}

Na madrugada de 3 de dezembro de 1984, um vazamento do gás isocianato de metila em uma fábrica de fertilizantes da multinacional norteamericana Union Carbide, em Bhopal, Índia, matou 3 mil pessoas diretamente. O desastre de Bhopal é o maior desastre tecnológico ocorrido na indústria química e acabou sendo construído como um dos principais pontos de discussão sobre a governança ambiental contemporânea (RAJAN, 2002).

$\mathrm{O}$ evento deflagrou questionamentos globais acerca dos processos de industrialização e das políticas econômicas praticadas especialmente por países subdesenvolvidos na década de 1980 . O jornal A Tribuna de Santos não só produziu reportagem sobre o tema, como também criou uma espécie de campanha após Bhopal, ainda mais porque a mesma empresa fabricava, em Cubatão, o fertilizante Temik, a base de isocianato de metila, importado dos EUA. O produto chegava à unidade da empresa pelo Porto de Santos (TS, 6 de dezembro de 1984). Com uma matéria de capa em 4 de dezembro, a edição de 4 de dezembro noticiava na manchete que o desastre de Bhopal havia provocado a morte de 350 pessoas (TS, 4 de dezembro de 1984). No dia seguinte, nova capa com a manchete "Mortos na Índia podem chegar a 2 mil", seguida de fotografia de corpos (TS, 5 de dezembro de 1984). A edição foi uma ótima oportunidade para retomar o tema da Vila Socó. Agora, o caso da vila interessava às autoridades estrangeiras que participavam do Simpósio sobre Emergências Causadas por Agentes Químicos, realizado pela CETESB (TS, 5 de dezembro de 1984).

O jornal assemelhava Bhopal e Vila Socó devido aos perigos do pós-desastre, às mortes, à amplitude e à intensidade dos desastres, às denúncias de negligência por parte das indústrias. Tal como no Brasil, no caso da Petrobrás, o jornal pontuava que desde 1982 as autoridades indianas eram informadas sobre os riscos de segurança da fábrica da Union Carbide (TS, 6 de dezembro de 1984). O Sindicato dos Petroquímicos de São Vicente, Santos e Cubatão afirmava que o risco existente em Bhopal não existia no Brasil, porque o isocianato de metila não era fabricado aqui (TS, 6 de dezembro de 1984). Contudo, estudo realizado por Pedro Tosta de Sá, em 1974, afirmava que os produtos que se destacavam em Cubatão pela alta toxicidade eram o pentachorofenol, da Rhodia, e o isocianato de metila, da Union Carbide (COUTO, 2003, p. 167).

A partirde 7 dedezembrode 1984, operiódico começou a pautar o armazenamento e o transporte do produto do porto de Santos para a Union Carbide de Cubatão. A empresa havia recebido 60 toneladas do produto e o jornal afirmava que os trabalhadores do porto sentiam-se inseguros e desinformados sobre os procedimentos a serem adotados com a carga, uma vez que não havia identificação adequada e clara sobre o isocianato de metila nas cargas. Segundo um dos portuários em depoimento ao jornal, "Vemos em muitos contêineres emblemas conhecidos e dizeres alarmantes, como inflamável, e desenhos aterradores como a tradicional caveira ou o emblema da espiga de milho com um x". O jornal ainda afirmara que os portuários estariam convictos 
de que a carga era de pó da china, provavelmente por ter ocorrido um evento semelhante, noticiado pela imprensa em 1982 (ÉPOCA, 24 de março de 1982 apud FERREIRA, 1991, p. 63).

Sob a manchete Carga química pode ter acesso ao centro urbano foi noticiado na página 8 da mesma edição de 7 de dezembro, que qualquer caminhão transportando produtos químicos como "nafta, benzeno, amônia, ou isocianato de metila (o produto que matou 1.200 pessoas na Índia) poderá circular pelas ruas de Cubatão". Segundo o vereador do PT, Dojival Vieira, ele próprio criou o projeto de lei que admitia a circulação de caminhões na área urbana de Cubatão, revogando assim uma lei municipal do prefeito, que proibia o estacionamento de caminhões com produtos inflamáveis explosivos, líquidos ou gasosos, mas permitia o estacionamento de caminhões transportando gasolina e gás liquefeito de petróleo (GLP) (TS, 7 de dezembro de 1984).

Ao que tudo indica, Dojival Vieira tinha como objetivo não prejudicar os caminhoneiros mas, segundo o discurso do jornal, a atitude da câmara dos vereadores de Cubatão em revogar a lei que proibia a circulação de caminhões na área urbana da cidade colocava em risco a população, pois tal lei havia sido criada devido a um vazamento de gás cloro ocorrido na Rua São Paulo, no centro de Cubatão (TS, 7 de dezembro de 1984).

No editorial do dia seguinte, intitulado "Baixada continua sob grave ameaça", o jornal $A$ Tribuna de Santos continuou a propagar um discurso de que o risco ultrapassasse as fronteiras políticoadministrativas das cidades da Baixada Santista. No editorial, o jornal questionava que em meio a tantos protestos contra a degradação do meio ambiente e à necessidade gritante de haver uma maior segurança quanto ao transporte de produtos químicos, as tragédias não paravam de ocorrer. Novamente, as fronteiras político-administrativas são transpostas para além da área urbana e industrial de Cubatão.

O jornal citava o desastre que aconteceu havia menos de um mês na estatal mexicana Petróleos Mexicanos (PEMEX) que, de maneira semelhante ao desastre de Vila Socó, provocou a morte de aproximadamente 650 pessoas devido à problemas no sistema de operações no transporte do Gás Liquefeito de Petróleo (GLP, além de ter ocorrido nas instalações de uma estatal como a Petrobrás (TS, 8 de dezembro de 1984). Após discorrer acerca do desastre no México, fazendo uma relação entre este último evento, os desastres de Vila Socó o desastre de Bhopal - considerando-o uma das maiores catástrofes de todos os tempos - o jornal indaga se a morte dos peixes e animais na Praia de Hermenegildo, no Rio Grande do Sul (1978), também não tenha sido provocada pelo isocianato de metila (TS, 8 de dezembro de 1984). Dizia o jornal: "O que está em jogo é a sobrevivência de aproximadamente um milhão de pessoas. [...] É exatamente a questão ambiental o problema vital pois trata exatamente da raiz de todos os males modernos: a insanidade do homem, que não pouca esforços para destruir sua própria fonte de vida" (TS, 8 de dezembro de 1984).

Apesar da sucessão de desastres tecnológicos que ocorreram desde o final dos anos 1970 até 1984 em Cubatão, noticiados pelo jornal A Tribuna de Santos, é importante salientar o peso simbólico desse ano como clímax de um momento em que muitos brasileiros apostavam nas mudanças políticas para reverter o quadro autoritário imposto havia duas décadas (KUSHNIR, 2004, p. 70).

$\mathrm{Na}$ edição de $1^{\circ}$ de janeiro de 1985 o jornal A Tribuna de Santos encerrava uma série de reportagem iniciada no dia 16 de dezembro de 1984, intitulada "Roteiro da Insegurança", trazendo na última página da edição de $1^{\circ}$ de janeiro de 1985 , o título "Insegurança é reflexo da opressão. Não se pode separar a questão ambiental do modelo político", o jornal mais uma vez apresentava uma crítica ao regime político que estava se encerrando, atribuindo a ele também os problemas ambientais de Cubatão e da Baixada Santista.

\section{A Tribuna de Santos e uma imprensa ambiental}

Cubatão era responsável, no início dos anos 1980, pela produção de $47 \%$ do hidrogênio brasileiro, $40 \%$ do aço, $38 \%$ dos fertilizantes, $32 \%$ do ácido fosfórico, $30 \%$ do polietileno, $18 \%$ do gás de cozinha e $12 \%$ da gasolina consumidos em 
território nacional, além de exportar alguns desses produtos (CARVALHO, 2017).

O cenário de desenvolvimento marcado pela industrialização, com todas as suas idiossincrasias regionais, especialmente quando nos referimos a desastres, serviu para a construção de muitos registros sobre eventos que foram acontecendo desde a década de 1970 e que vieram a transbordar em inúmeras narrativas de desastres, especialmente na década seguinte. No caso de Cubatão, enquadrada aqui como uma sociedade industrial marcada pela distribuição desigual da riqueza, é preciso pensar, também, na distribuição desigual dos riscos e a imprensa acabou construindo espaço peculiar de visibilidade e problematização dessa temática em um momento em que a atenção ao ambiente na imprensa nacional não era primordial (BELMONTE, 2015; RAMOS, 1995), especialmente porque os jornalistas precisavam sempre amparar suas leituras em cientistas e, pelo fato de existir um controle sobre o que produzir e o que publicar, tanto jornalistas quanto cientistas eram coagidos a não se pronunciar (CARVALHO, 2017).

A construção de uma "cidade técnica", na concepção do governo autoritário que enquadrou Cubatão como área de segurança nacional e, logo em seguida, tirou a liberdade do município de proibir a instalação de empresas poluentes, em 1975, a ênfase na tecnicidade serviu, também, para permitir a emergência da circulação não só de culturas industriais (a instalação de empresas multinacionais na região desde os anos 1960), mas também a circulação dos riscos tecnológicos a elas vinculados.

Na pretensão de adotar e controlar sistemas tecnológicos, os acidentes industriais na região passavam, pelo menos até os anos 1970, como eventos "normais" de uma sociedade industrial. Um dos aspectos da normalidade residia especialmente nos reflexos da confiança demasiada na tecnologia como agente de controle e transformação positiva de problemas advindos do próprio processo de modernização (PARROW, 1984).

Os desastres de Cubatão na década de 1980 foram sendo construídos discursiva, social e materialmente e a imprensa desempenhou papel fundamental no processo por permitir a leitura das experiências desastrosas, em meio às práticas políticas e científicas em torno deles. A TS, nesse sentido, foi-se constituindo e sendo reconhecida pela cobertura e pela construção de uma nova narrativa de desastres, na medida em que termos como insegurança, poluição, aliança entre poluição e desenvolvimento desenfreado foram adentrando suas páginas.

Ao considerar o espaço de construção discursiva dos desastres pela Tribuna, podemos pensar que a base "técnica" (FERREIRA, 1991, p. 62), que sustentava o regime, que na verdade era política e econômica com fragilidades ambientais fundamentais serviram como esteio para a emergência de questionamentos acerca de uma racionalidade tecnocrática acerca das decisões tomadas em âmbito regional de Cubatão.

O cenário da redemocratização, o enfraquecimento do poder do regime autoritário, as mobilizações em torno das "Diretas Já", em 1984 e o vislumbramento de novas questões a serem discutidas na esfera pública e que diziam respeito ao bem-estar da população, tais como poluição, contaminação e segurança alimentar, típicas de sociedades modernas convivendo com processos de industrialização ou desindustrialização, ditariam o compasso dos debates que começavam a surgir, na imprensa, em torno do progresso, do desenvolvimento, da tecnologia e da ciência, e de diferentes regimes de verdade nos quais a tônica não seria mais apenas a política por si mesma, mas a política entremeada pela temática ambiental.

\section{Notas}

$1 \mathrm{O}$ militar Arthur Levy era graduado em engenharia, tendo sido conselheiro do Conselho Nacional do Petróleo (1945-1954), diretor da Petrobrás (1953-1954), presidente da Petrobrás (1954-1956), superintendente geral da Refinaria Duque de Caxias (1961-1962) e Presidente da Associação Brasileira de Normas Técnicas (ABNT) (1967 e 1969). Além disso, foi membro da Comissão do Anteprojeto de Legislação do Petróleo (1947); membro no setor de combustíveis da Missão ABBINK (1948); chefe da construção da rede de oleodutos Santos-São Paulo (1948/1952); membro da Comissão de Localização da refinaria de Cubatão (1952/1953); presidente da Comissão de Estudos da Rede de Oleodutos Nacionais 
(1953); presidente da I Comissão Especial das Indústrias Petroquímicas (1952-1954). No campo da iniciativa privada trabalhou como diretor da Empresa de Construção e Pavimentação (ECOPA) e da Betanil Indústrias Químicas (1973). Fonte: Fundação Getúlio Vargas. Guia dos Arquivos do CPDOC-FGV. Disponível em: $\quad<$ http://www.fgv.br/cpdoc/guia/detalhesfundo. aspx?sigla=AL $>$. Acesso em: 21 jul. 2017.

2 As áreas críticas em termos de poluição eram as regiões metropolitanas de São Paulo, Rio de Janeiro, Belo Horizonte, Recife, Salvador, Porto Alegre e Curitiba, as regiões de Cubatão e Volta Redonda e as bacias hidrográficas do Médio e Baixo Tietê, Paraíba do Sul, Jacuí, Pernambuco e o estuário do Guaíba.

3 Para Ferreira (1991), o elemento catalisador do debate sobre Cubatão foi "a divulgação de casos de anomalias congênitas e sua possível correlação com os índices elevados de saturação ecossistêmica" (FERREIRA, 1991, p. 100). Além da CEV e da CEI, outras entidades que funcionavam como articuladores políticos para promover o debate sobre Cubatão eram o Partido dos Trabalhadores (PT), a Pastoral Operária, as igrejas Católica, Metodista e Anglicana, a Sociedade Beneficente de Vila São José (Vila Socó), o Comitê de Defesa de Vila Parisi, a Associação das Vítimas da Poluição e das Más Condições de Vida de Cubatão (AVPMCVC), a Sociedade Brasileira de Ecologia (SBE) e a Sociedade Brasileira para o Progresso da Ciência (SBPC), informalmente representada pelo jornalista Randáu Marques (FERREIRA, 1991, p. 112-113).

$4 \mathrm{O}$ incêndio em Vila Socó foi noticiado por The New York Times (EUA) e La Vanguardia (Espanha), em 26 de fevereiro de 1984; Le Monde (França) e Camberra Times (Austrália), em 28 de fevereiro de 1984, além da Times Magazine, do jornal The Washington Post, entre outros.

\section{Referências}

A FOLHA DE SÃO PAULO. São Paulo, edição de 12 jun. 1984.

A TRIBUNA DE SANTOS. Santos, edições de 24 fev. 1984; 27 fev. 1984; 29 fev. 1984; $1^{\circ}$ mar. 1984; 2 mar. 1984; 4 mar. 1984; 9 mar. 1984; 5 dez. 1984; 6 dez. 1984; 7 dez. 1984; 8 dez. 1984 e 24 dez. 1984.

\section{ASSOCIAÇÃO DE COMBATE A POLUENTES} (ACPO). Disponível em: <http://www.acpo.org.br/ caso_rhodia.htm $>$. Acesso em: 12 set. 2017.

BELMONTE, R. V.História do jornalismo ambiental brasileiro. $1^{\circ}$ Encontro Nacional de História da Mídia, 2015. Disponível em: <http://www. ufrgs.br/alcar/encontros-nacionais-1/encontrosnacionais/10o-encontro-2015/gt-historia-dojornalismo/historia-do-jornalismo-ambientalbrasileiro/at_download/file>. Acesso em: 15 set. 2016.

BRASIL. Secretaria do Planejamento. II Plano Nacional de desenvolvimento: 1975-1979. Brasília, DF, 1974.

BRASIL. Decreto n. 76.389, de 1975. Dispõe sobre as medidas de prevenção e controle da poluição industrial, de que trata o Decreto-Lei $\mathrm{n}^{\circ} 1.413$, de 14 de agosto de 1975, e dá outras providências. Disponível em: <http://www2.camara.leg.br/legin/ fed/decret/1970-1979/decreto-76389-3-outubro1975-424990-publicacaooriginal-1-pe.html>. Acesso em: 12 jul. 2016.

BRASIL. Lei 5.449/1968. Declara de interesse da segurança nacional, nos termos do art. $16, \S 1^{\circ}$, alínea b, da Constituição, os Municípios que especifica, e dá outras providências. Disponível em: <http:// www2.camara.leg.br/legin/fed/lei/1960-1969/lei5449-4-junho-1968-359221-publicacaooriginal-1pl.html>. Acesso em: 12 jul. 2016.

BUELL, L. Writing for an endangered world. Boston: Harvard University Press, 2011.

COUTO, J. M. Entre estatais e transnacionais: o polo industrial de Cubatão. 2003. Tese (Doutorado em Ciências Econômicas) - Instituto de Economia, Universidade Estadual de Campinas, Campinas, 2003.

CARVALHO, R. E. de. Cubatão e o jornalismo ecológico: estudo de três momentos. Disponível em: <http://www.portcom.intercom.org.br/pdfs/4 f0dd33b95cdc4902f09df7e41b4e7e4.pdf >. Acesso em: 18 set. 2017.

DEAN, W. A ferro e fogo: a história e a devastação da Mata Atlântica brasileira. São Paulo: Companhia das Letras, 2000.

ESPÍNDOLA, M. A.; NODARI, E. S.; LOPES, A. R. S. História Ambiental e Interdisciplinaridade 
na análise de desastre. In: Simpósio Internacional sobre Interdisciplinaridade no Ensino, na Pesquisa e na Extensão Região Sul, 2013, Florianópolis. Anais do Simpósio Internacional sobre Interdisciplinaridade no Ensino, na Pesquisa e na Extensão Região Sul. Florianópolis: PPGICH/ UFSC, 2013. v. 1.

ESPÍNDOLA, M. A.; NODARI, E. S.; LOPES, A. R. S. (Orgs.) Desastres socioambientais em Santa Catarina. São Leopoldo: Oikos, 2015.

FARO, Diego do Prado. II Plano Nacional de Desenvolvimento e Modelo de Substituição de Importações. 2010. (Monografia) Graduação em Ciências Econômicas. Universidade Estadual de Campinas, Campinas, 2010.

FERREIRA, L. C. Os fantasmas do vale: representações e modos de ação social em Cubatão. Dissertação (Mestrado em Sociologia) - Instituto de Filosofia e Ciências Humanas, Universidade Estadual de Campinas, Campinas, 1991.

FERREIRA FILHO, C. A (toxi)cidade de Cubatão: história ambiental, desastres tecnológicos e a construção do imaginário ambiental da cidade tóxica na década de 1980. 2015. Dissertação (Mestrado em História) - Universidade Estadual do Centro Oeste. Irati, 2015.

FUNDAÇÃO GETÚLIO VARGAS. Guia dos Arquivos do CPDOC-FGV. Disponível em: $<$ http://www.fgv.br/cpdoc/guia/detalhesfundo. aspx?sigla $=\mathrm{AL}>$. Acesso em: 21 jul. 2017.

GOLDENSTEIN, L. A industrialização da Baixada Santista: estudo em centro industrial satélite. 1972. Tese (Doutorado em Geografia) - Universidade de São Paulo, São Paulo, 1972.

HALLISON PUBLICIDADE LTDA. Cubatão, ontem e hoje: um marco do desenvolvimento. São Paulo: Hallison Publicidade, 1970.
HOGAN, D. J. Condições de vida e morte em Cubatão. In: Anais do VI Encontro Nacional de Estudos Populacionais. Olinda: Abep, 1988.

KLANOVICZ. História ambiental e desastres: encontros entre política, tecnologia e sociedade. História Unisinos, v. 17, p. 293-302, 2013.

KUSHNIR, B. Cães de guarda: jornalistas e censores, do AI-5 à constituição de 1988. São Paulo: Boitempo/FAPESP, 2004.

OLIVER-SMITH, A. What is a Disaster: Anthropological perspectives on a persistent question. In: (Ed.) The Angry Earth: Disaster in Anthropological Perspective. London: Routledge, 1999.

O ESTADO DE SÃO PAULO. São Paulo, edição de 4 de fevereiro de 1981.

São Paulo, edição de 18 de fevereiro de 1982.

RAJAN, R. Disaster, development and governance: reflections on the 'lessons' of Bhopal. Environmental Values, v.11, n. 3, p. 369-394, 2002.

PARROW, C. Normal accidents: living with high risk technologies. New York: Basic Books, 1984.

PEREIRA,E.M.Aética doconvívioecossustentável: uma biografia de José Lutzenberger. 2016. Tese (Doutorado em História) - Programa de Pósgraduação em História. Universidade Federal do Rio Grande do Sul, Porto Alegre, 2016.

RAMOS, L. F. A. Meio ambiente e meios de comunicação. São Paulo: AnaBlume, 1995.

VEJA. O inferno de Cubatão. São Paulo, ed. 691, p. 50-54, 2 dez. 1981. 